\title{
THE CONCEPT OF CUMULATIVE TRAUMA IN TIMES OF COVID-19: COULD KHANS THEORY BECOME USEFUL AGAIN?
}

\author{
Gianluca Crepaldi, \& Pia Andreatta \\ Institute of Psychosocial Intervention, University of Innsbruck (Austria)
}

\begin{abstract}
The paper discusses whether the psychoanalytic concept of Cumulative Trauma could be a valuable theoretical contribution in understanding possible traumatization's of children in the course of the Covid-19 pandemic, as they may quite often face a multiple stressed parent during a lockdown, who's parental function is on the verge breaching. This concept of trauma as established by British Psychoanalyst Masud Khan in 1963 was hardly taken into account in recent trauma research and it has seen little discussion in psychodynamic literature; if at all, it has been used as a merely descriptive category, without considering the suspension of the parental care function, which was identified as the decisive traumatogenic factor for the child's traumatization. The paper begins with a recapitulation of the original theory and then moves on to linking the Cumulative Trauma to current research contexts (attachment, mentalization, developmental trauma disorder). Finally, the relevance of the concept for parenting in times of the Covid-19 pandemic is explored on the basis of a short clinical case example.
\end{abstract}

Keywords: Cumulative trauma, parent-child interaction, mentalization, pandemic stress, Covid-19.

\section{Introduction}

The term "cumulative trauma" has - if at all - been used descriptively in trauma research in recent years, most of the time to describe an accumulation of psychological stress in childhood or adulthood, which in sum can lead to symptoms or a diagnosis of PTSD (for example Tagay et al., 2013; Karam et al., 2014; Muenzenmaier et al., 2014; Wilker et al., 2015). However, the original theoretical construct formulated by the psychoanalyst Masud Khan (1963) locates the aetiopathogenesis of Cumulative Trauma in some sort of damaged parental caretaking, insofar a parent is unable to perform his or her function as a protective shield for the child. This aspect is hardly mentioned anymore, even within the psychoanalytic discourse (Crepaldi \& Andreatta, 2020). We therefore understand the present paper as an attempt to take a new look at this concept that has been lost from view and ask, if it could be a valuable contribution to understand possible traumatization's of children in the course of the Covid-19 pandemic, as they may quite often face a multiple stressed parent during a lockdown, whose parental function is on the verge breaching. In a first step, Khan's trauma theory must be reconstructed in its basic elements; building on this, we want to link the concept with today's research contexts - especially attachment and mentalization research - and point out similarities to diagnostic constructs such as the so-called Developmental Trauma Disorder (van der Kolk, 2009). The article then closes with general considerations on the possible relevance of the concept for parenting in times of the Covid-19 pandemic. A short case example is presented, in which a single mom seeks a psychoanalyst because she fears her pandemic induced stress might in the long run lead to the traumatization of her children.

\section{Masud Khans theory of cumulative trauma}

Object-relations theorist Masud Khan (1963) develops the idea of the potentially traumatogenic effect that emanates from a damaged or impaired caretaking function of the mother. The resulting „trauma syndrome" is defined as follows:

„My argument is that cumulative trauma is the result of the breaches in the mother's role as a protective shield over the whole course of the child's development, from infancy to adolescence-that is to say, in all those areas of experience where the child continues to need the mother as an auxiliary ego to support his immature and unstable ego functions. [...] Cumulative trauma thus derives from the strains and stresses that an infant-child experiences in the context of his ego dependence on the mother as his protective shield and auxiliary ego" (Khan, 1963, p. 290f). 
The "breaches in the mother's role as protective shield" explicitly refer to Freud's (1920g) formulation of a "breach in the stimulus protection" (p. 31) of an organism through a shock-like influence from the outside. However, Khan's Cumulative Trauma does not aim at overt and massive abuse and deprivation scenarios to which children are exposed over a long period of time, rather it refers to the accumulation of more subtle inconsistencies in mother-child interaction. In this context, Grubrich-Simitis (1979) appropriately speaks of "inconspicuous failures of empathy", which take place primarily in preverbal, affective interaction processes between mother and infant and lead to a disruption of the earliest structural formation of the infants personality, especially concerning its ability for self-object differentiation. The unreliability and instability in the maternal care function, which is by no means to be misunderstood as intentional and which normally serves the child as a protective shield against sensual or affective overstimulation from inside or outside, have a pathogenic effect. The breaches or interruptions in the protective shield or stimulus-protective function of maternal care (or more broadly formulated: the early holding environment), "collide" with the unprotected child's "psyche-soma" and cumulate "silently and invisibly" through the developmental process. "They achieve the value of trauma only cumulatively and in retrospect" (Khan, 1963, p. 291). As a result, a latent "nucleus of pathogenic reaction" (ibid., p. 298) is implemented in the child's personality structure, which forms the basis of later trauma reactions or symptoms caused by the Cumulative Trauma, which can appear for the first time many years after the actual traumatisation.

Khan does explicitly not aim at acute psychopathologies of mothers (e.g. psychotic episodes); he rather thinks of a recurring maladaptation and deficient responsiveness of the caregiver in relation to the dependence and neediness of her child. In particular, those stages in which the child develops a great "hunger for stimulation" are said to be especially sensitive; in the optimal case, they would be accompanied by maximum affectual adaptation on the part of the caretaker, who protects against stimulus overload through empathic attention. According to Khan, this maternal or parental function as a protective shield is never to be understood passively; rather, it is an "alert, adaptive and organising one" (ibid., p. 295). The cause of insufficiently adjusted "caretaking" is found in "intrusions" of the parents' own stresses, which restrict them in their autonomous ego functions and their sensitive perceptive capacity. Parental stress states indirectly affect the infant or toddler, whereby the children's reactions can vary greatly depending on the frequency, duration and intensity of those "breaches" in the caretaking function. The theory illustrates the insidious, silent and invisible emergence of trauma as a result of some kind of introjection of subtraumatically stressful pre-verbal events into the child's internal object-relations. The traumatic quality of these cumulating breaches is constituted retrospectively. Due to "a great inherent resilience" of children (ibid., p. 300), the Cumulative Trauma will often only emerge later in life (often during adolescence), for example as a reaction to acute stress or psychosocial crisis.

\section{The theory of cumulative trauma in the light of current research contexts}

Almost 60 years after the publication of the concept of Cumulative Trauma, we want to discuss its connections to current approaches to be able to assess its relevance for today's questions. Those links or thematic overlaps can be found in areas such as attachment theory, developmental trauma and mentalization research.

\subsection{Attachment and developmental trauma}

Summarizing central findings of attachment research, Brisch (2013) states that "severe emotional deprivation as well as experiences of maltreatment and abuse [...] represent a significant cause for the development of disorganized attachment patterns as well as attachment disorders" (p. 38). Analogously, Wöller (2009) speaks of disorganized attachment being "very clearly related to maltreatment, neglect and severe disturbances of the dyadic adjustment processes between mother and child" (p. 43), which play a decisive role in the aetiology of severe personality disorders in adulthood. When caregivers themselves are those "who inflict the traumatization on the child", in the vast majority of cases because they themselves have experienced abuse and maltreatment, and their child is "overwhelmed by feelings of existential threat and devastating disregard" during the time of the first attachment experiences, primary attachment trauma takes place (Rauwald, 2013, p. 26). The decisive factor is that attachment needs have been "inadequately, insufficiently or contradictorily responded to to an extreme degree" (Brisch, 2013, p. 40). This has serious consequences for the formation of internal representations of the self and the object: "The inner working models of attachment are subject to fragmentation or destruction processes in particularly bad and persistent deprivation experiences" (ibid.). Clinical studies have shown that the highest proportion of disorganisedly attached children (up to $77 \%$ depending on the study) had abusive parents. Clinically, the consequences can manifest as borderline personality disorder in adolescence, attention deficit syndrome or other externalizing behavioral disorders. The attachment pattern must be 
assumed to be a mediating variable here; disorganized attachment is a vulnerability factor, secure attachment a protective factor. From the perspective of the attachment paradigm, the "loss of the secure base" (Wöller, 2009, p. 43) through maltreatment, abrupt separation and abuse has a traumatic effect.

Based on these findings from attachment research, but also from neurobiology and other relevant research on trauma in children, van der Kolk (2009) and his working group have long been calling for a more precise diagnosis for children with complex interpersonal traumatization and propose the introduction of a new trauma syndrome in the international diagnostic classification systems, especially since "most traumatised children do not meet the diagnostic criteria of PTSD" (p. 580) and there is "no other diagnostic entity that describes the profound impact of trauma on child development" (p. 579). His concept of "Developmental Trauma Disorder" (DTD), which was not included in the DSM-5, lists as diagnostic criterion $A$ "chronic exposure to one or more developmentally disabling interpersonal traumas (abandonment, betrayal of trust, physical assault, sexual assault, threats to physical integrity, coercive practices, emotional abuse, witnessing violence and death)" (ibid., p. 581). If caregivers are repeatedly "emotionally absent, inconsistently frustrating, violent, overwhelming or neglectful" (ibid., p. 576), the child cannot learn to regulate internal states. This leads to neurobiological changes, among other things, because "chronic traumatization [...] impairs the ability to integrate sensory, emotional and cognitive information". Deficits in emotional self-regulation problems (e.g. lack of impulse control, insecurity, mistrust of others, attention deficits, dissociative symptoms) can emerge in adolescence and adulthood and lead to disorders such as drug addiction, borderline or antisocial personality disorder, eating disorders, but also into numerous somatic disease patterns (cardiovascular, metabolic and immune diseases) (ibid., p. 579).

\subsection{Mentalization}

Khan (1963) points out that his theoretical construct of the "protective shield", is ultimately about something very concrete: the role of the caretaking parent in the immediate vis-à-vis to her child. A detailed scientific examination of fault prone micro-processes of affect attunement and mirroring between caregiver and child, their internalization by the child and possible pathogenic consequences for the child's personality development can be found within the context of modern mentalization research (Fonagy et al., 2004); despite its comprehensive review and innovative integration of attachment theory, cognitive psychology, neurobiology and psychoanalysis, there is no reference to Cumulative Trauma, despite the fact that mentalization researchers understand inadequate affect attunement to be traumatizing for the child.

Fonagy and his research group (2004) distinguish two "deviant styles of affect mirroring" (pp. 200 ff.). (1) When mothers are overwhelmed by negative affect states of their infants or toddlers, they sometimes respond by simply reproducing this negative affect. The child's emotions are reflected in an undigested form. The negative emotion cannot be detached from the mother, it is experienced by the child as belonging to the other, and the representation of his own affective state - which is urgently needed for the maturation of his ego functions and his autonomous affect regulation ability - is missing. Thus, instead of a successful affect modulation, "a traumatization occurs" (ibid., p. 201). The prevalence of this deviant form of affect mirroring is also a predictor of the child's later development of a personality disorder. (2) The second deviant style would be a type of distorted mirroring, for example, when the mother perceives her own child's positive arousal distorted as aggression. The child internalizes this distorted mirroring and, on this basis, develops a "distorted secondary representation" of its own emotions and subsequently a "false" self-image or a so-called "false self". In order to avoid the complete disintegration of the self, these "alienating" or threatening elements must be externalized by the child. Consequences of this deviant affect mirroring are an insufficient formation of object constancy and thus, in the long run, a high dependence on the physical presence of another person (e.g., caregivers, partners, therapists, etc.) that take over the regulation of the self.

These deviant mirroring types described by Fonagy et al. (2004) correspond to an astonishing extent with Khan's "breaches in the protective shield" due to the intrusion of stresses, which either lead to the offer of a "symbiosis or rejective withdrawal" by the parent (Khan, 1963, p. 295). Also, the concept of the "false self" formulated by Winnicott (1956), which Fonagy and colleagues refer to in their texts, is already used in Khan's original contribution for the theoretical explanation of character-pathological consequences of the suspension of maternal care. The child, overwhelmed by the lack of stimulus protection, attempts to empathize with the mother, which can lead to distortions of the ego, the body-ego, and subsequently to disruption of the development of a mature self. In a sense, the child begins to establish an over-sensitivity to the maternal mood, which disrupts the development of a coherent ego and creates a false identificational unity with the mother (Khan, 1963, p. 298). 
To sum it up: Khan's concept, which has been linked to attachment and mentalization research, relocates what is potentially traumatizing to the quality of the primary object relation, which can at the same time constitute a crucial protective factor against distressing influences from within or without. An intact parental care function must include the ability to appropriately mentalize affectual states of the child. The parental ability to mentalize develops based on good enough attachment experiences in their own childhood; however, this emphasis on the early childhood development of mentalizing skills leaves "little room for their later loss through trauma in adolescence or adulthood" (Dornes, 2004, p. 190). And indeed, a reading of Khan (1963) suggests that when he was raising the issue of Cumulative Trauma he was not thinking primarily of parents with so-called attachment and personality disorders, but rather of stressors or traumas experienced by parents in their adulthood.

\section{Exploring the relevance of cumulative trauma for parenting in times of the Covid-19 pandemic}

In this final section, we'd like to discuss the question whether the concept of Cumulative Trauma might be a helpful contribution in better understanding stressors and traumatization experienced by children through their parents in times of Covid-19. As has been widely reported in the media, the current pandemic and its counter measures are a heavy stress factor for parents and caretakers all over the world. There is now enough convincing empirical evidence, to support the thesis, that pandemic induced stress has a massive negative effect on parenting. For example, Chung et al. (2020) have shown in their study, that the high parental stress during lockdown measures was associated with increased use of harsh parenting and less parent-child relationship closeness. Many similar studies have been conducted, but the long-term effects of cumulative exposures might not be immediately visible in children. It is quite remarkable, that Khan already points out "the difficulty in detecting them clinically in childhood. They gradually get embedded in the specific traits of a given character structure" (Khan 1963, p. 291). This could imply, that many children are being silently and invisibly traumatized by an accumulation of poorly adapted or disrupted interactions with their parents, who can currently be overwhelmed by pandemic induced stress. To illustrate this unproven hypothesis, we would like to give a short case example from clinical practice:

A 28-year-old single mother with two daughters (two and a half years old and five years old) is seeing a psychoanalyst because she is suffering from the consequences of the lockdown measures in Austria and she fears that her condition could have negative long-term effects on the psychological development of her children. Over the course of months, she must take care of both of her daughters all by herself and do her work for local social services in her small apartment using her private laptop. The kindergarten refuses to take in the children during the lockdown, by arguing that only parents with so-called system-relevant jobs would be allowed to use childcare services. During the therapy sessions, the patient impressively describes her permanent demands due to job tasks (emails, telephone calls, writing reports) and the various needs of her daughters. Even the simplest everyday errands can bring her to the brink of despair. Her inner experience fluctuates permanently between struggling against depressive feelings on the one hand and heavy anxiety of a complete emotional breakdown on the other. The descriptions of interaction sequences with her children stand out in particular, in which she is absent and emotionally unavailable; she experiences the caretaking of her children like an inanimate administrative task. During these periods, the children get into states of arousal more easily and are much harder to calm down. Some days, the children seem resigned and barely make eye contact with their mother. On other days the children try to provoke emotional reaction of their mother by annoying her with yelling, fighting and disobeying. When the stress becomes almost unbearable, the patient describes something that feels to her like a "breach" in her "mental functioning" (remarkably using almost the exact same term as Khan in his original concept). A small external stimulus (e.g. a loud noise from the neighbor's apartment) is then enough to cause aggressive impulse breakthroughs. In these acute situations, she screams excessively at her daughters until her voice fails. Once, she even breaks one of her daughter's toys in front of her. After acting-out, she feels the urge to leave the room and the children to themselves for several minutes. In the aftermath of those events, she is plagued by severe feelings of shame and guilt.

Psychological stress theory (Lazarus \& Folkman, 1984) - which could offer a theoretical frame for our case - defines stress as a product of a transaction between a person (including multiple systems: cognitive, physiological, affective, psychological, neurological) and his or her environment. How an individual appraises a stressor determines how he or she copes with or responds to the stressor. However, from a psychodynamic perspective the interpersonal dimension of the individuals stress experience, which manifests itself in the phenomenon of counter-transference, is a crucial aspect to measure the quality of a stressor. The psychoanalyst in this specific case example reacts to the heavy burden of his patient presented to him throughout many sessions by occasionally drifting away in a slightly dissociative state. Now it is him, that is emotionally unreachable. Dissociative states that appear in the therapist's counter-transference often point to the traumatic quality in the experience of the patient. When we look at this clinical case material through the lens of Khans theory, it becomes obvious, that the mother's role as 
a protective shield for her children is severely impaired. She herself describes and experiences situations, in which she is overwhelmed by stress, as "breaches" in her "mental functioning". Her capacity for mentalizing or adequately mirroring her children's affectual states as well as her sensitive and responsive adaptiveness towards her children's needs seem to be suspended. Could circumstances like these lead up to the point where, as Khan puts it, a nucleus of pathogenic reaction is implanted in the child's personality? How long must a stressful situation like this last and which quality it must have, to become a Cumulative Trauma? It would certainly be interesting to do further research focusing on the children, because severe psychological consequences of the pandemic could become apparent in the next generation.

\section{Concluding remark}

We propose that it would be worthwhile to resume the discussion on Cumulative Trauma, because it adds an explicit psychodynamic perspective on the traumatic quality of accumulating stress. This could be a valuable addition to psychological stress theories. Also, the extent of connectivity of Khans concept with current research (attachment, mentalization, developmental trauma), is quite a surprising finding, considering that this is an older psychoanalytic theory that has seen little discussion since it was first published. It will be necessary to take a further look at how stressors like the pandemic have an effect on parenting and therefore on the next generation. Further clinical and empirical evidence would be desirable.

\section{References}

Brisch, K.-H. (2013). Die Weitergabe von traumatischen Erfahrungen von Bindungspersonen an die Kinder. In M. Rauwald (Ed.), Vererbte Wunden. Transgenerationale Weitergabe traumatischer Erfahrungen. Weinheim: Beltz Juventa.

Chung, G., Lanier, P. \& Wong, P.Y.J. (2020). Mediating Effects of Parental Stress on Harsh Parenting and Parent-Child Relationship during Coronavirus (COVID-19) Pandemic in Singapore. J Fam Viol. https://doi.org/10.1007/s10896-020-00200-1

Crepaldi, G., Andreatta, P. (2020). M. Masud R. Khan (1963). Das kumulative Trauma. Forum Psychoanal 2020 (online first). https://doi.org/10.1007/s00451-020-00403-8

Dornes, M. (2004). Über Mentalisierung, Affektregulierung und die Entwicklung des Selbst. Forum Psychoanal, 20, 175-199. https://doi.org/10.1007/s00451-004-0195-4

Fonagy, P., Gergely, G., Jurist, E. \& Target, M. (2004). Affektregulierung, Mentalisierung und die Entwicklung des Selbst. Stuttgart: Klett-Cotta.

Freud, S. (1920g). Jenseits des Lustprinzips. GW XIII, 1-69.

Grubrich-Simitis, I. (1979). Extremtraumatisierung als kumulatives Trauma. Psychoanalytische Studien über seelische Nachwirkungen der Konzentrationslagerhaft bei Überlebenden und ihren Kindern. Psyche - Z Psychoanal, 33, 991-1023.

Karam, E., Friedman, M. et al. (2014). Cumulative traumas and risk thresholds: 12-month PTSD in the World mental health surveys. Depression and Anxiety, 31, 130-142. https://doi.org/10.1002/da.22169

Khan, M. M. R. (1963). The Concept of Cumulative Trauma. The Psychoanalytic Study of the Child, 18, 286-306. https://doi.org/10.1080/00797308.1963.11822932

Lazarus, R. S., \& Folkman, S. (1984). Stress, appraisal, and coping. New York: Springer.

Muenzenmaier, K., Schneeberger, A., et al. (2014). Stressful childhood experiences and clinical outcomes in people with serious mental illness: A gender comparison in a clinical psychiatric sample. J Fam Viol, 29, 419-429. https://doi.org/10.1007/s10896-014-9601-x

Rauwald, M. (2013). Traumata. In M. Rauwald (Ed.), Vererbte Wunden. Transgenerationale Weitergabe traumatischer Erfahrungen. Weinheim Beltz: Juventa.

Tagay, S., Repic, N., et al. (2013). Traumatische Ereignisse, psychische Belastungen und Prädikatoren der PTBS-Symptomatik bei Kindern und Jugendlichen. Kindheit und Entwicklung, 22, 70-79. https://doi.org/10.1026/0942-5403/a000102

Van der Kolk, B. (2009). Entwicklungstrauma-Störung: Auf dem Weg zu einer sinnvollen Diagnostik für chronisch traumatisierte Kinder. Prax Kinderpsychol Kinderpsychiat, 58, 572-586. https://doi.org/10.13109/prkk.2009.58.8.572

Wilker, S., Pfeiffer, A., et al. (2015). How to quantify exposure to traumatic stress? Reliability and predictive validity of measures for cumulative trauma exposure in a post-conflict population. European Journal of Psychotraumatology, 6. https://doi.org/10.3402/ejpt.v6.28306

Winnicott, D. W. (1956). Primary Maternal Preoccupation. Collected Papers. New York: Basic Books. Wöller, W. (2009). Trauma und Persönlichkeitsstörungen. Stuttgart: Schattauer. 